Review

\title{
Capillary electrophoresis as a metabolomics tool for non-targeted fingerprinting of biological samples
}

\author{
C. Barbas ${ }^{a, *}$, Edgar P. Moraes ${ }^{a, b}$, A. Villaseñor ${ }^{a}$ \\ a CEMBIO (Center for Metabolomics and Bioanalysis), Facultad de Farmacia, Universidad San Pablo-CEU, Campus Montepríncipe, Boadilla del Monte, 28668 Madrid, Spain \\ ${ }^{\mathrm{b}}$ University of Sao Paulo, Brazil
}

\section{A R T I C L E I N F O}

\section{Article history:}

Received 7 October 2010

Received in revised form 31 January 2011

Accepted 1 February 2011

Available online 3 March 2011

\section{Keywords:}

Metabolomics

Metabonomics

Pattern recognition

Biomarkers

\begin{abstract}
A B S T R A C T
Metabolomics, understood as a data driven strategy trying to find markers of a situation under study without a priori hypothesis, has rapidly caught the attention and evolved from the simple pattern recognition strategy, which was a great innovation at its origins, to the interest for the final identification of markers responsible for class separation, i.e., from data to knowledge. Due to differences in physico-chemical properties and concentrations of the metabolites, but also due to differences in matrix properties, crossplatform approaches are proving to increase the capability of information. Once more techniques do not compete. This is the scene where capillary electrophoresis (CE) has its niche to provide information mainly on polar or ionic compounds in biological fluids.

General advantages and disadvantages of CE for sample fingerprinting will be discussed and methods will be classified depending on the detection system (UV or MS) as this strongly affects all the conditions. Recent developments will be presented in different biological fluids, although urine is without a doubt the preferred sample for CE analysis.
\end{abstract}

(c) 2011 Elsevier B.V. All rights reserved.

\section{Contents}

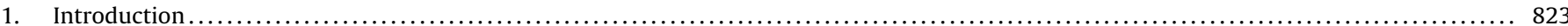

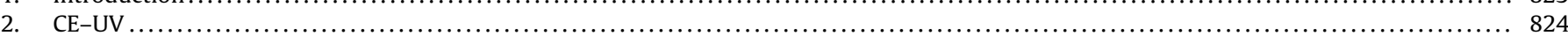

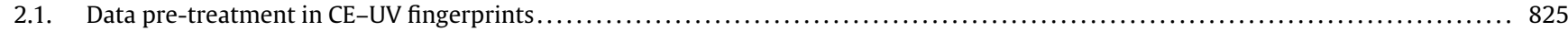

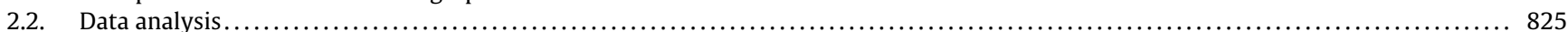

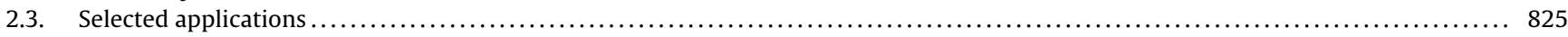

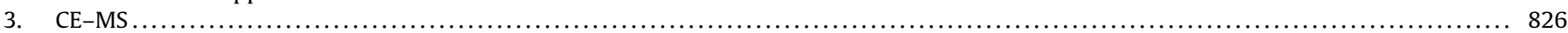

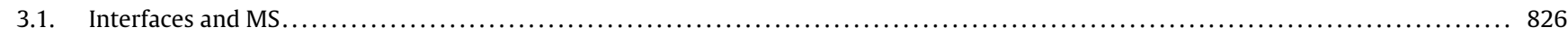

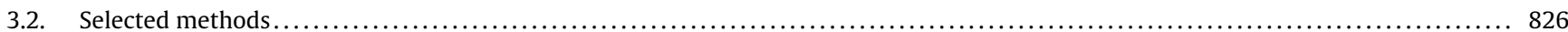

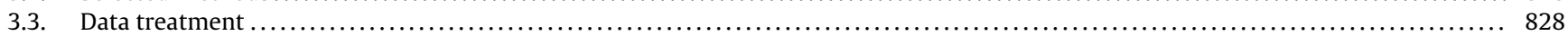

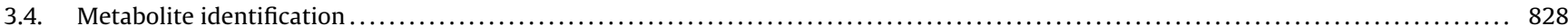

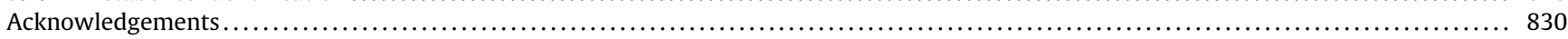

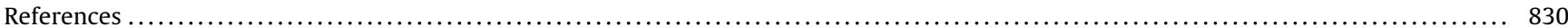

\section{Introduction}

The metabolome has been defined as the qualitative and quantitative collection of all low molecular weight molecules (metabolites) present in a cell that are participants in general metabolic reactions and that are required for the maintenance, growth and normal function of a cell [1].

\footnotetext{
* Corresponding author. Tel.: +34 913 724711; fax: +34 913510475.

E-mail address: cbarbas@ceu.es (C. Barbas).
}

Metabolites include wide variations in chemical (molecular weight, polarity, solubility) and physical (volatility, charge) properties. The degree of diversity includes ionic polar compounds, such as oxalate, low molecular weight (MW), volatile organic metabolites (urea), to the higher MW, polar (carbohydrates) and non-polar (terpenoids and lipids) metabolites. In addition, concentrations also extend over an estimated 7-9 orders of magnitude in concentration (pmol-mmol).

Metabolite analysis is not new; what is really new is the way we approach the problem. An omics technology has come to mean an approach capable of generating a comprehensive data 
set of whatever is being measured be it, genes (genomics), transcripts (transcriptomics), proteins (proteomics), or metabolites (metabol(n)omics). This is not only a new terminology, but also a real new approach to the analytical problem and with very different analytical requirements.

Thus with all metabolites as a goal in metabolomics, the technological obstacle seems to be the limiting step, being increasingly recognized that the combination of several techniques is currently the only possible approach.

Capillary electrophoresis has been considered a newcomer to the analytical tool box in metabolomics for years and honestly the adjective is becoming old-fashioned. CE is a technique that has not succeeded to get the main stream in analytical laboratories due to some drawbacks, but with a really high analytical potential for those who accomplish an expertise on it. Through this review we will critically discuss strengths and drawbacks of CE for metabolomics.

Classical analysis, both metabolite target analysis and metabolic profiling [2], is developed with the expectation that a measurement or combination of several measurements of related compounds reveals something about a specific problem or situation. For example, changes in oxalate and citrate reveal kidney problems. The analytical tools from sample treatment to the analytical method and adequate standards for calibration are specifically selected.

In an "omic" methodology the expectation is that the response pattern of numerous analytes, both known and unknown, is reflective of a situation and the comprehensive nature of the data set enables evaluation of systemic response. As an example, the urine fingerprint obtained with capillary electrophoresis of mice infected with schistosomiasis can be clearly differentiated from controls [3]. The end point to increase the knowledge about the pathology should be the identification of the specific biomarkers, being chemometrics a compulsory tool to approach data treatment.

Capillary electrophoresis in the simplest mode, capillary zone electrophoresis (CZE) is a separation technique based, on the differential transportation of charged species in an electric field through a conductive medium. Therefore, primary candidates for CE separation are ions. Since $C E$ is based on a different separation mechanism to HPLC it also shows different selectivity and has been considered orthogonal and complementary to chromatography. Within CE systems, selectivity can be modified by changing the polarity, coating the capillaries or modifying the electrolyte. In MEKC, neutral solutes will partition with the micelles in a chromatographic way and selectivity differences can be caused by changing the nature and concentration of the surfactant. There is a huge bunch of possibilities, although some of them are limited by the detection technique employed, mainly in the case of mass spectrometry.

Main advantages of capillary electrophoresis compared with other analytical techniques used for biofluids fingerprinting:

(i) Small sample requirement (a few nanolitres), which is particularly well-suited when analysing valuable biological fluids through different analytical techniques.

(ii) Minor sample treatment. Just enough to avoid capillary clogging, because capillaries are rinsed after each run and apparently no irreversible retention is produced. That is good for a true metabolomic approach.

(iii) Ability to separate compounds in aqueous media. The main components of biological fluids display high polarity and water-solubility which makes them hard to retain on reversedphase stationary phases. That makes it a suitable technique alternative to HPLC.

(iv) Capability of providing information complementary to mass, because analytes migration is based on mass to charge ratio.

(v) High efficiency which means high resolution (vi) Multiple modes can be applied on the same sample to generate a broader picture what is closer to a real "omic" technique.

\section{Main drawbacks}

(i) Robustness is a weak point. That means in practice shifts in retention time which complicate serial analysis.

(ii) Sensitivity, because the volume of sample injected is in the nanoliters range and the cell pathway (the capillary diameter) is very narrow in UV. In MS commercially available interfaces require a sheath liquid which dilutes the analyte bands.

The preparation of samples for metabolomic analysis when a general fingerprint is the objective should be minimal to prevent any loss of metabolites. However, many important endogenous metabolites exist at very low concentrations in biological systems and the use of sample preconcentration techniques is often necessary to increase the sensitivity for the low-abundance endogenous metabolites. However, this topic is out of our focus.

The aim of this review is summarizing the state-of-art of capillary electrophoresis applied to biological sample fingerprinting. Due to the fact that the detection system is the component that most affect method development, data treatment and possible outcome of the measurements that will be the criterion for organizing the review.

There are several previous reviews with different coverage of the topic that can be complementary: Monton and Soga [4] described technical considerations and selected metabolomic applications of CE-MS; Ramautar et al. [5] demonstrated the applicability of CE in different fields of metabolomics research with illustrative clinical, bacterial and plant examples. The authors mainly focus on selected groups of metabolites, i.e. metabolic profiling, more than comprehensive fingerprinting, the review was later updated [6]. Barbas et al. reviewed the field of CE fingerprinting including four main blocks: sample treatment, analytical methods, chemometrics and applications heading focuses in urine, plasma, organic matter and plant extract studies [7]. Within a specific set of compounds, a recent review focuses on the analysis of nucleosides as metabolites of either oxidative DNA damage or RNA's turnover that are used as the potential tumor markers [8].

\section{CE-UV}

CE with UV detection is a really simple tool, when compared to more sophisticated ones such as ${ }^{1} \mathrm{H}$ NMR or mass spectrometry. Nevertheless, it has proved to be very useful for many applications and it would be an easy to transfer technique for field and routine analysis.

In a pioneering work Hanna-Brown et al. showed how sulphated b-CD-modified MEKC can be used to provide a useful tool for urine fingerprinting, allowing for separations of more than 80 signals in under 25 min [9]. In addition, Barbas and coworkers [10] showed that CE separations performed with reverse polarity, using polyacrylamide-coated capillaries, can provide the separation of over 60 signals in urine samples in around $25 \mathrm{~min}$. They also proved that the possibility of measuring the same samples in CE operating with both two different polarities and buffer systems affords the exciting opportunity of having a truly holistic metabolomics approach, since all compounds in a given sample can then be resolved and detected in one or other mode, with the only limitation being UV sensitivity [11]. By using urine from control and diabetic rats, the complementarity of both CE methods, regarding the compounds detected in each one, was proved, and both were validated for a selected set of compounds with migration times across the total migration time window (for each mode). Com- 
pounds fitting these criteria were, for the normal polarity CD-MEKC method: urea, creatinine, allantoin, hippuric acid and uric acid (as representative of cations and neutral compounds eluting first, followed by only large anions or weak acids at the end of the profile); and for the reverse polarity CZE method: oxalic, citric, benzoic and hippuric acids (showing mainly short chain organic acids from smaller to higher $m / z)$.

\subsection{Data pre-treatment in CE-UV fingerprints}

Once obtained the omic fingerprint, before pattern recognition methods can be used for classification, preprocessing techniques for the denoising, baseline removal, normalisation and alignment of electropherograms must be applied.

$\mathrm{CE}$ in comparison to high performance liquid chromatography (HPLC) or gas chromatography (GC) produces less reproducible results, what may pose a problem in long lasting projects. Variations in migration time - a function of electroosmotic flow (EOF) inside the capillary, sample loading, wall interactions and physical errors (such as injection irreproducibility or temperature variations) may lead to poorly reproducible data and preclude their appropriate interpretation [12] This is the most challenging point, while all the others share methodology with HPLC data pre-treatment and are well established.

Several methods have been proposed for signal alignment without prior knowledge of the compounds present; dynamic time warping (DTW) [13]; correlation optimised warping (COW) $[14,15]$; parametric time warping (PTW) $[16,17]$. The choice of a suitable method depends on the problem at hand. The DTW uses distance as a measure of similarity of two signals. However, in case of chromatographic signals, DTW is sensitive to different peak intensities. Therefore Nielsen proposed another approach, where the correlation coefficient is used as a similarity measure of two signals. PTW is based on a parametric model of warping functions that are created for calibration samples and then used in the correction of a whole batch of data. Different experiments have shown that the COW offers a better similarity measure [18,19].

Soria et al. [20] achieved alignment by combining the use of reference peaks with a method that uses information from multiple wavelengths to align electropherograms to a reference signal.

Bro et al. [21] suggested handling retention time shifts using the PARAFAC2 model. There is no need to align signals to equal length prior to data modeling, because the model does not assume parallel elution profiles. In this approach a covariance matrix of elution profiles preserving its 'inner-product structure' from sample to sample is used. PARAFAC2 is not a method for aligning as such, but it allows treating retention time shifts in chromatograms. It should be stressed that the method is suited for trilinear data, it means that it cannot be used for the univariate signals [22].

\subsection{Data analysis}

Data analysis is performed with common multivariate data analysis tools with each data point or peak area as a variable and using both non-supervised such as Principal Component Analysis (PCA) and supervised such as Partial Least Square Discriminant Analysis (PLS-DA) methods. There is no difference regarding data treatment with other metabolomic tools and the question is out of this review.

\subsection{Selected applications}

Urine fingerprints from control and diabetic rats have shown the clear effects of an antioxidant treatment on diabetic animals [23], which were not seen in controls, in a rapid, simple and costeffective way without identifying a single marker. Classification was supported by that produced after PCA and PLS-DA of target variables obtained with selectively designed, time and reagent consuming methods [24]. Once developed, the methodology can be easily applied for a rapid in vivo screening of extracts with potential in vitro activity.

Among them, Dunaliella salina extracts were tested [25]. This is a microalga with high content in carotenoids that can be extracted via an environmentally clean process such as supercritical fluid extraction with $\mathrm{CO}_{2}$. Five doses of $D$. salina extract with in vitro antioxidant properties were intragastrically administrated to adult male streptozotocin (STZ) diabetic rats. D. salina extract induced changes showed up by the multivariate analysis. Results of the treatment from most of the parameters can be considered beneficial for diabetic animals; although an increase in hyperglycemia and 8-isoprostane excretion when STZ treated animals received the extract was observed.

Schistosoma mansoni infection in mice has been fingerprinted using CE to study the capabilities of this technique as a diagnostic tool for this parasitic disease [3]. Results were compared with ultra high performance liquid chromatography-MS (UHPLC-MS) by applying the same set of multivariate analysis tools [26]. Principal component analysis of the aligned data provided a time trajectory where the infection was observed after 30 days with UPLC-MS and CE. Orthogonal partial least-square discriminant analysis models were validated for sensitivity and specificity. Multivariate data analysis derived from two different detection systems showed that CE-UV and UPLC-MS found equivalent results. In addition a validation was performed with samples from two sets of mice infected in an inter-laboratory experiment where different infection methods and animal husbandry procedures were employed in order to establish the core biological response to a S. mansoni infection. CE data were analysed using principal component analysis [27]. Validation of the scores consisted of permutation scrambling (100 repetitions) and a manual validation method, using a third of the samples (not included in the model) as a test or prediction set. The validation yielded $100 \%$ specificity and $100 \%$ sensitivity, demonstrating the robustness of these models with respect to deciphering metabolic perturbations in the mouse due to a $S$. mansoni infection. A total of 20 metabolites across the two experiments were identified that significantly discriminated between $S$. mansoni-infected and noninfected control samples.

Working with this model, chemometric tools have been applied to improve information extraction, which is probably the weak point of the technique: Matlab-based software employing the Pearson's correlation algorithm was applied to urine electropherograms from 20 mice infected with the schistosoma parasite [28]. The fingerprints were the sum of electropherograms analysed with normal and reverse polarity, in two different modes MEKC and CZE and with two different capillaries (uncoated and polyacrylamide coated) to provide a broad picture of the samples. Hippurate, a metabolite that was depleted in the infected group and is present in both polarities, was chosen as a test variable; it correlated with itself to a $p$ value of $\leq 0.001$. Phenylacetylglycine, was positively correlated to three metabolites in its same pathway. The study shows that the autocorrelation matrix is able to provide extra information from data files acquired by CE analyses.

Correlations were not only established within the same technique, but also with ${ }^{1} \mathrm{H}$ NMR. The two sets of metabolic profiles were first processed and analysed independently and were subsequently integrated using statistical correlation methods in order to facilitate cross assignment of metabolites. These correlation analyses facilitated structural elucidation using the identification power of one technique to enhance and validate the other, but also highlighted the enhanced ability to detect functional correlations between metabolites, thereby providing potential for achieving deeper mechanistic insight into the biological process [29]. 
In even more challenging assays CE-UV was used in human experiments where differences are not only due to disease or treatment but also genetic, environmental, nutritional and every kind of differences exists.

CE-UV was used to detect possible differences in urine of diabetic children as compared to controls [30]. Afterwards, children were enrolled in a trial to evaluate the effect of a special additive containing rosemary extract, vitamin E and PUFAs added to their standard diet through the meat to test a possible nutraceutical effect. Clear differences could be observed between treated and non-treated diabetic children and some of the metabolites associated could be identified. Fig. 1 shows the most representative metabolites identified in urine for each CZE in reverse polarity and MEKC in normal polarity.

CE was also employed to fingerprint bile collected at $10 \mathrm{~min}$ increments in the donors and in the recipients [31]. The electropherograms of these samples were aligned and normalised using correlation optimised warping algorithms and modelled with multivariate techniques. The resulting metabolic signatures were compared; in general donors and recipients showed distinct fingerprints and clustered separately. This study proposes CE fingerprinting of human bile as a promising technique to help unravel the complex metabolic pathways involved during transplantation.

Different strategies have been developed and successfully applied with CE-UV for profiling a specific set of compounds such as nucleosides, hormones and others in human biofluids, however the review will focus on non-target metabolite fingerprinting.

\section{CE-MS}

When coupling these two techniques the final result depends strongly on the characteristics of the interface system and type of mass spectrometer.

\subsection{Interfaces and MS}

Regarding the electrical interfacing, there are two types of instruments: (i) with the CE outlet capillary connected at ground and the electrospray voltage applied from the MS, which makes CE separation conditions independent from MS operation conditions, (ii) the end of the capillary is at a high voltage and it is reduced or increased by the electrospray voltage. In addition to the closure of the electrical circuit, a hydraulic flow rate is required to form the electrospray and two approaches have been developed, one the sheath flow interface, is commercially available and the other the sheathless interface has many publications, because dilution occurs at the mixing point, sensitivity tends to be compromised but is still under research. This problem can be avoided with a review by Zamfir [32] summarizes the state of the art. In any case, the optimization of a number of parameters: sheath liquid flow rate and composition, nebulizing gas, electrospray voltage, temperature, and some others are part of the method development in CE-MS.

One of the recent developments in interfaces for metabolomics [33] is related to a method that enables metabolomic fingerprinting of single cells and subcellular structures. A nebulizer-free coaxial sheath-flow interface completes the circuit and provides a stable electrospray, yielding a signal with a relative standard deviation of under $5 \%$ for the total ion electropherogram. Detection limits are in the low nanomolar range (i.e., $50 \mathrm{nM}(300 \mathrm{amol})$ ) for a number of cell-to-cell signaling molecules, including acetylcholine (ACh), histamine, dopamine, and serotonin. Single-cell electropherograms are reproducible, with a large number of metabolites detected; more than 100 compounds yield signals of over 104 counts from the injection of only $0.1 \%$ of the total content from a single metacerebral cell. Expected neurotransmitters are detected within the cells, as are compounds that have molecular masses consistent with all of the naturally occurring amino acids (except cysteine).

Regarding the ionization process, electrospray ionization (ESI) enables direct transfer of molecules from the liquid phase to the gas phase and it is in practice the only ion source employed in metabolomics.

Almost all types of mass analyzers have been coupled to CE. However, the typically narrow peaks resulting from CE separations, in addition to sample complexity require high mass accuracy and high resolution to be able to resolve closely migrating components with similar nominal masses. For that reason TOF are used in most of the applications.

Obviously the CE-MS coupling offers the structural identification capabilities of both mass spectrometer and migration time relationship to structure. Nevertheless, buffer systems and, therefore, separation modes have the typical constrains of MS, which are restricted to volatile buffers such as acetate and formiate. Recently Veuthey et al. [34] have reviewed fundamental concepts instrumental considerations and applications of the most widely used coupling in metabolomics: CE-TOF/MS.

\subsection{Selected methods}

Due to technical limitations both in CE migration and MS ionization a comprehensive analysis requires two or more sets of conditions, which have been optimised for different compound groups, and then concatenate the results. Amino acids, amines and nucleosides are analysed as cations using a very low $\mathrm{pH}$ electrolyte [35].

This was the case for Ramautar et al. [36] while studying urine of chronic patients with complex regional pain syndrome. Compounds with a higher number of amine groups in their structure, such as lysine or arginine, migrated first (10-11 min). Next a group of metabolites comprising amino acids (e.g., valine, leucine, threonine, pro line), vitamins (e.g., carnitine) and amines (e.g., creatine and $\mathrm{N}$-methylnicotinamide) migrated together with small peptides like phenylalanine-glycine (12-14 min). Subsequently, the slower migrating amino acids comprising phenyl moieties (such as phenylalanine and tyrosine) migrated and then nucleosides like guanosine (14-17 min). Acidic metabolites, such as hippuric acid, are slightly anionic at $\mathrm{pH} 1.8$ and, therefore, migrate just after the EOF. Similarly Minami et al. detected 953 peaks from blood plasma samples in mice. Among these peaks, 44 peaks exhibit significant circadian oscillations [37].

On the other hand, carboxylic acids, phosphorylated carboxylic acids, phosphorylated saccharides, nucleotides, and nicotinamide and flavinadenine coenzymes can be analysed as anions using an alkaline BGS and a cationic polymer-coated capillary (SMILE $(+))$ to reverse the EOF and prevent deleterious current drops [38]. For anions analysis Harada et al. [39] proposed a different approach based on pressure-assisted capillary electrophoresis coupled to electrospray ionization mass spectrometry. The feature of this method is that CE polarity is inverted from conventional CE analysis for anions, where the inlet of the capillary is at the anode and the outlet at the cathode. Moreover, an ordinary fused silica capillary was chosen instead of a specific cationic polymer-coated capillary (SMILE $(+)$ capillary). A robust and inexpensive analytical method was established from the above-mentioned CE polarity and noncoated fused silica capillary. A trimethylamine acetate electrolyte, $\mathrm{pH} 10.0$, provides a high resolution between isomers. Electrolyte flow using an air pump after electrophoresis enables the comprehensive and simultaneous analyses of sugar phosphates, organic acids, nucleotides and a CoA compound. According to the authors method can be used as a de facto standard for metabolome analysis. 

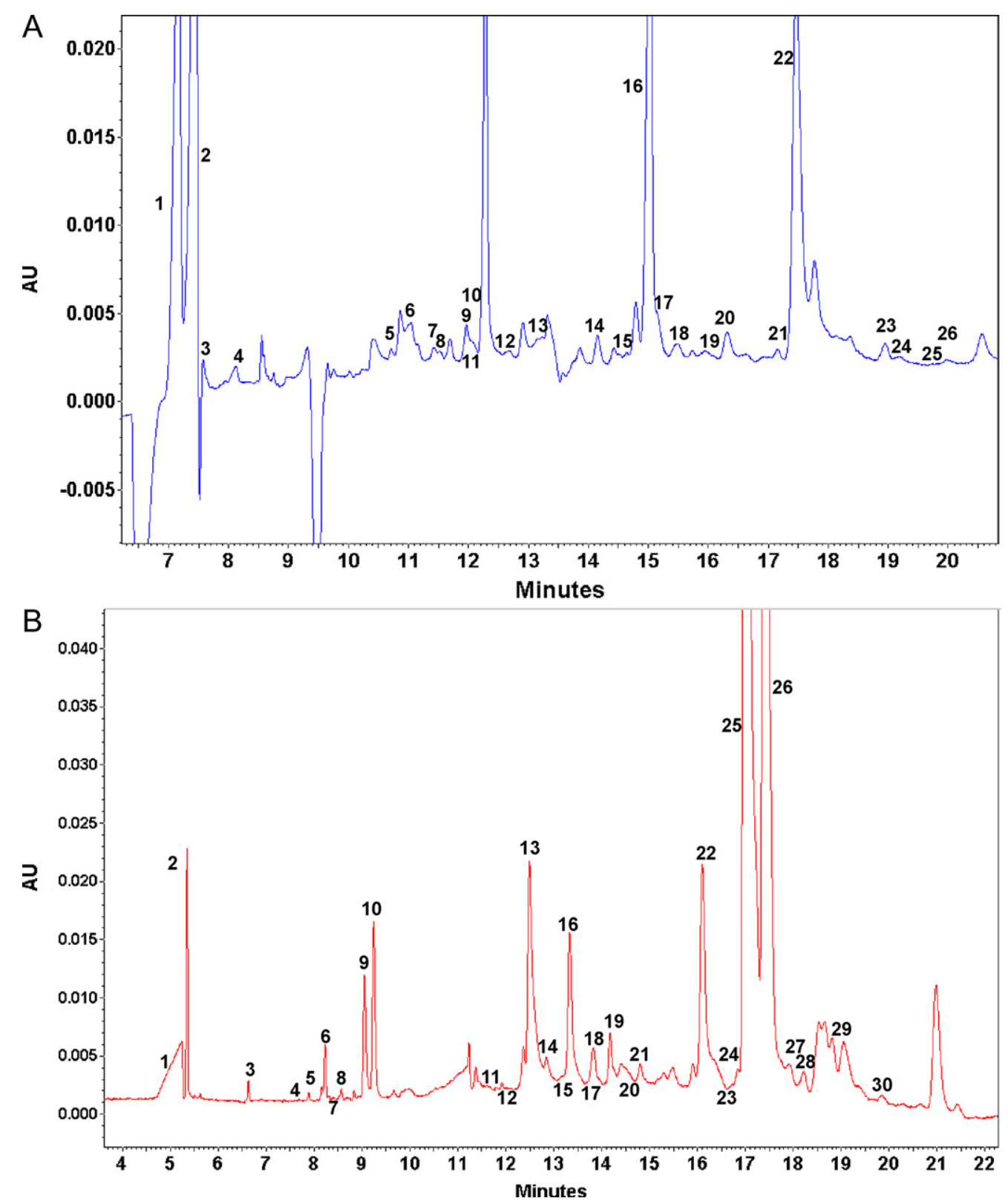

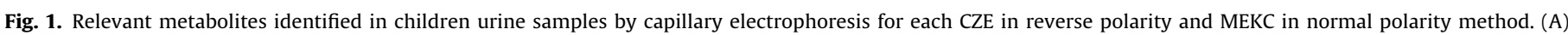

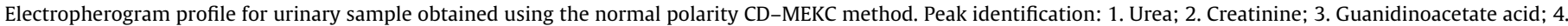

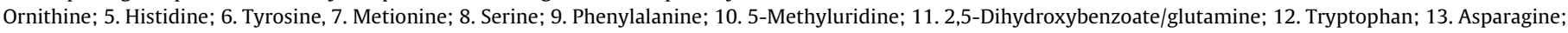

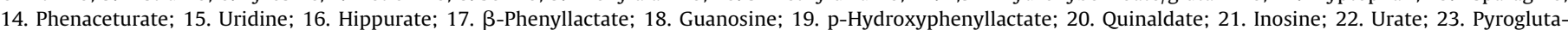

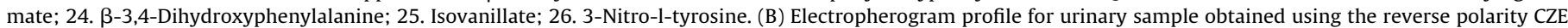

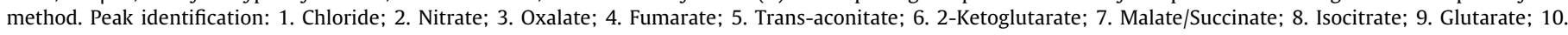

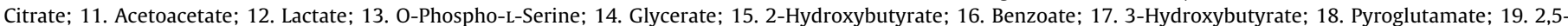

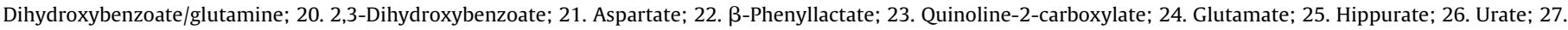
p-Hydroxyphenyllactate; 28. Homovanillate; 29. Vanillylmandelate/2-aminoadipate; 30. Glucuronate (from [30]).

Only one paper has used pressurized capillary electrochromatography CEC ( $\mathrm{pCEC}$ ) with gradient elution for the metabolomic study of urinary samples [40] as an alternative chromatographic separation tool with higher degree of resolution, selectivity, sensitivity, and efficiency. The pCEC separation of urinary samples was performed on a RP column packed with $\mathrm{C} 18,5 \mu \mathrm{m}$ particles with an ACN/water mobile phase containing TFA. The effects of the acid modifiers, applied voltage, mobile phase, and detection wavelength were systematically evaluated using eight spiked standards, as well as urine samples. A typical analytical trial of urine samples from Sprague Dawley rats exposed to high-energy diet was carried out following sample pretreat- ment. Significant differences in urinary metabolic profiles were observed between the high energy diet-induced obesity rats and the healthy control rats at the 6th week postdose. Multivariate statistical analysis revealed the differential metabolites in response to the diet, which were partially validated with the putative standards

Soga et al. [41] for the first time published the approach for the comprehensive and quantitative analysis of charged metabolites by capillary electrophoresis mass spectrometry with the two methods applied on the same samples. Their method enabled the determination of 352 metabolic standards and its utility was demonstrated in the analysis of 1692 metabolites from Bacillus subtilis extracts, 
revealing significant changes in metabolites during B. subtilis sporulation.

Benavente et al. [42] also investigated a heterogeneous mixture of biologically relevant compounds in body fluids covering a broad range of physicochemical properties to optimise separation conditions in fused-silica capillaries. A running electrolyte containing $50 \mathrm{mM}$ of acetic acid and $50 \mathrm{mM}$ of formic acid at $\mathrm{pH} 2.5$ was used for the CE separations. A sheath-flow electrospray interface was employed for CE-ESI-MS analysis. Sheath liquids containing $80: 20(\mathrm{v} / \mathrm{v})$ methanol/water with $0.1 \%(\mathrm{v} / \mathrm{v})$ of acetic acid or $60: 40$ $(\mathrm{v} / \mathrm{v})$ isopropanol/water with $0.5 \%(\mathrm{v} / \mathrm{v})$ of ammonia were selected for optimum detection in positive and negative ESI modes, respectively.

The usefulness of noncovalently coated capillaries with layers of charged polymers was investigated by Ramautar et al. [43] to obtain global electrophoretic fingerprints of urinary metabolites covering a broad range of different compound classes in a highly repeatable way. Capillaries were coated with a bilayer of polybrene (PB) and poly(vinyl sulfonate) (PVS), or with a triple layer of PB, dextran sulfate (DS) and PB. The bilayer and triple layer coatings were evaluated at acidic ( $\mathrm{pH} 2.0)$ and alkaline ( $\mathrm{pH}$ 9.0) separation conditions, thereby providing separation conditions for basic and acidic compounds. A representative metabolite mixture and spiked urine samples were used for the evaluation of the four CE methods. Approximately, 600 molecular features were detected in rat urine by the PB-DS-PB CE-MS method whereas about 300 features were found with the PB-PVS CE-MS method. With regard to the analysis of anionic compounds by CE-MS, in general analyte responses were significantly lower than that for cationic compounds, most probably due to less efficient ionization and to ion suppression effects caused by the background electrolyte.

Lately Soga's group [44] optimised the method in the negative mode using a platinum electrospray ionization spray needle. They proved that the material in the spray needle had significant effect on the measurement of anions. A stainless steel spray needle was oxidized and corroded at the anodic electrode due to electrolysis. The use of a platinum ESI needle prevented both oxidation of the metals and needle corrosion. Sensitivity using the platinum needle increased from several- to 63-fold, with the largest improvements for anions exhibiting high metal chelating properties such as carboxylic acids, nucleotides, and coenzyme A compounds.

As a model study, human urine samples, obtained after intake of coffee, tea, or water, were analysed with capillary electrophoresis electrospray ionization time-of-flight mass spectrometry (CE-ESI-TOF-MS) [45]. In the model study highly significant differences due to beverage intake were obtained among the 10 first principal components.

A differential metabolomics strategy by capillary electrophoresis-electrospray ionization-mass spectrometry (CE-ESI-MS) to assess the efficacy of nutritional intervention to attenuate oxidative stress induced by strenuous exercise [46]. Time-dependent changes in global metabolism of filtered red blood cell lysates by CE-ESI-MS were measured to reveal a significant attenuation of cellular oxidation associated with high-dose oral $\mathrm{N}$-acetyl-L-cysteine intake relative to a control. Untargeted metabolite profiling allowed for the identification and quantification of several putative early- and late-stage biomarkers that reflected oxidative stress inhibition due to nutritional intervention, including oxidized glutathione (GSSG), reduced glutathione (GSH), 3-methyl-histidine (3-MeHis), L-carnitine (CO), O-acetyl-L-carnitine (C2), and creatine (Cre).

Saliva is another readily accessible and informative biofluid, making it ideal for the early detection of a wide range of diseases including cardiovascular, renal, and autoimmune diseases, viral and bacterial infections and, importantly, cancers [47]. The authors conducted a comprehensive metabolite analysis of saliva samples obtained from 215 individuals ( 69 oral, 18 pancreatic and 30 breast cancer patients, 11 periodontal disease patients and 87 healthy controls) using capillary electrophoresis time-of-flight mass spectrometry (CE-TOF-MS). They identified 57 principal metabolites that can be used to accurately predict the probability of being affected by each individual disease.

Untargeted metabolomic analyses were performed by CE-ESI-MS on irradiated leukocytes exposed to increasing doses of radiation emitted from a Taylor source, which were subsequently incubated for $44 \mathrm{~h}$ to allow for cellular recovery [48]. CE-ESI-MS analysis of filtered white blood cell lysates was performed to quantify changes associated with 22 intra-cellular metabolites, which were consistently measured in leukocytes across all radiation levels.

Most cancer cells predominantly produce energy by glycolysis rather than oxidative phosphorylation via the tricarboxylic acid (TCA) cycle, even in the presence of an adequate oxygen supply (Warburg effect). However, little has been reported regarding the direct measurements of global metabolites in clinical tumor tissues. Capillary electrophoresis time-of-flight mass spectrometry was applied to simultaneously measure their levels in tumor and grossly normal tissues obtained from 16 colon and 12 stomach cancer patients [49]. Quantification of 94 metabolites in colon and 95 metabolites in stomach involved in glycolysis, the pentose phosphate pathway, the TCA and urea cycles, and amino acid and nucleotide metabolisms resulted in the identification of several cancer-specific metabolic traits. Extremely low glucose and high lactate and glycolytic intermediate concentrations were found in both colon and stomach tumor tissues, which indicated enhanced glycolysis and thus confirmed the Warburg effect. Significant accumulation of all amino acids except glutamine in the tumors implied autophagic degradation of proteins and active glutamine breakdown for energy production, i.e., glutaminolysis. In addition, significant organ-specific differences were found in the levels of TCA cycle intermediates, which reflected the dependency of each tissue on aerobic respiration according to oxygen availability.

\subsection{Data treatment}

Baseline correction, dataset normalisation and alignment, and the detection of significant differences between metabolite profiles through multivariate data analysis can be performed with the same tools as used for LC-MS. However, optimised software tools for CE-MS are needed [50] because of the sometimes large variation in migration time between runs and the wider variety of peak shapes in CE-MS data compared with LC-MS or GC-MS. Therefore, we implemented a stand-alone application named JDAMP (Java application for Differential Analysis of Metabolite Profiles), which allows users to identify the metabolites that vary between two groups. Soga's group has developed JDAMP with that purpose.

\subsection{Metabolite identification}

A major obstacle in metabolomics remains the identification and quantification of a large fraction of unknown metabolites in complex biological samples when purified standards are unavailable. Sugimoto et al. [51] have developed a method to identify unknown peaks based on the predicted migration time (tm) and accurate $\mathrm{m} / \mathrm{z}$ values. They developed a predictive model using 375 standard cationic metabolites and support vector regression. The model yielded good correlations between the predicted and measured tm. Using the trained model, they subsequently predicted the tm for 2938 metabolites available from the public databases and assigned tentative identities to noise-filtered features in human urine samples. While $38.9 \%$ of the peaks were assigned metabolite names by 
Table 1

CE applications for biofluid fingerprint in metabolomics.

\begin{tabular}{|c|c|c|c|c|}
\hline Fluid & Pathology & Method & Markers & Reference \\
\hline $\begin{array}{l}\text { Urine, blood, liver and } \\
\text { plasma }\end{array}$ & Diabetes & $\begin{array}{l}\text { CD-MEKC } 25 \mathrm{mM} \text { sodium tetraborate decahydrate, } 75 \mathrm{mM} \\
\text { SDS and } 6.25 \mathrm{mM} \text { sulphated bcyclodextrin, pH 9.50, } 2.25 \% \\
\text { (v/v) HFIP, } 20 \mathrm{kV}, 20 \mathrm{C} \text {. CZE polyacrylamide coated } \\
\text { capillary, } 0.2 \mathrm{M} \text { phosphoric acid, pH } 6.10,10 \% \mathrm{MeOH} \text {, } \\
-25 \mathrm{kV}, 20 \mathrm{C}\end{array}$ & & [25] \\
\hline Red blood cell & Theoretical work & $\begin{array}{l}\text { CE-ESI-MS electrolite } 1.4 \mathrm{M} \text { formic acid, } \mathrm{pH} 1.8 \text {, sheath } \\
\text { liquid } 1: 1 \mathrm{MeOH} / \mathrm{H}_{2} \mathrm{O} \text { with } 0.1 \% \mathrm{FA}, 25 \mathrm{kV}, 20 \mathrm{C}\end{array}$ & $\begin{array}{l}\text { Amino acids, amines, } \\
\text { peptides, } \\
\text { acylcarnitines, } \\
\text { nucleosides }\end{array}$ & {$[52]$} \\
\hline Urine & Schistosoma & $\begin{array}{l}\text { MECK } 25 \mathrm{mM} \text { sodium borate, } 75 \mathrm{mM} \text { SDS and } 6.25 \mathrm{mM} \\
\text { sulphated b-cyclodextrin, pH 9.5, } 18 \mathrm{kV}, 20 \mathrm{C} \text { and CZE } 0.2 \mathrm{M} \\
\text { phosphate, } 10 \% \mathrm{MeOH}, \mathrm{pH} 6.2\end{array}$ & $\begin{array}{l}\text { Hippurate and } \\
\text { phenylacetyl-glycine }\end{array}$ & [28] \\
\hline Tumor tissues & Colon and stomach cancer & $\begin{array}{l}\text { CE-TOFMS cationic - BGE } 1 \mathrm{M} \text { formic acid. SL } 1: 1 \\
\mathrm{H}_{2} \mathrm{O} / \mathrm{MeOH}, 0.5 \mu \mathrm{M} \text { reserpine, } 30 \mathrm{kV}, 20 \mathrm{C} \text { CE-TOFMS } \\
\text { anionic, cap cationic polymer-coated SMILE }(+)-\mathrm{BGE} \\
50 \mathrm{mM} \text { ammonium acetate, pH } 8.5 \text {, SL ammonium acetate } \\
(5 \mathrm{mM}), 1: 1 \mathrm{MeOH} / \mathrm{H}_{2} \mathrm{O}, 1 \mu \mathrm{M} \text { reserpine, }-30 \mathrm{kV}\end{array}$ & 95 metabolites & [49] \\
\hline Neurons & Study of neural functions & $\begin{array}{l}\text { CE-ESI-MS electrolite } 1 \% \text { formic acid, sheath liquid } 1: 1 \\
\mathrm{MeOH} / \mathrm{H}_{2} \mathrm{O} \text { with } 0.1 \% \mathrm{FA}, 20 \mathrm{kV}\end{array}$ & $\begin{array}{l}\text { Neurotransmitters } \\
\text { including acetylcholine } \\
\text { (ACh), histamine, } \\
\text { dopamine, and } \\
\text { serotonin }\end{array}$ & [33] \\
\hline Mouse liver & Oxidative stress & $\begin{array}{l}\text { CE-TOFMS negative mode-coated with a cationic polymer } \\
\text { BGE } 50 \mathrm{mM} \text { acetic acid (pH 3.4), SL } 5 \mathrm{mM} \text { ammonium } \\
\text { acetate in } 50 \%(\mathrm{v} / \mathrm{v}) \text { methanol-water containing } 0.1 \mu \mathrm{M} \\
\text { Hexakis, }-30 \mathrm{kV}, 20 \mathrm{C}\end{array}$ & Anionic metabolites & {$[44]$} \\
\hline Red blood cell & Oxidative stress & $\begin{array}{l}\text { CE-ESI-MS cationic mode - BGE } 1.0 \mathrm{M} \text { formic acid, pH } 1.8 \text {, } \\
\text { SL } 0.1 \% \text { formic acid in } 1: 1 \mathrm{MeOH} / \mathrm{H}_{2} \mathrm{O}-\text { negative mode - } \\
\text { BGE } 50 \mathrm{mM} \text { ammonium acetate } \mathrm{pH} 8.5 \text {, SL } 5 \mathrm{mM} \\
\text { ammonium acetate in } 1: 1 \mathrm{MeOH} / \mathrm{H}_{2} \mathrm{O}, 30 \mathrm{kV}, 20 \mathrm{C}\end{array}$ & Glutathione & {$[54]$} \\
\hline Urine & Diabetes & CE-UV & Antioxidants & [23] \\
\hline Urine & Urinary tract infection & $\begin{array}{l}\text { CE-TOFMS capillaries noncovalently coated, electrolite } 1 \mathrm{M} \\
\text { formic acid, } \mathrm{pH} 1.8 \text {, sheath liquid } 50 / 50 \mathrm{H}_{2} \mathrm{O} / \mathrm{MeOH} 0,1 \% \\
\text { FA, } 30 \mathrm{kV}, 25 \mathrm{C}\end{array}$ & Amino acids & [55] \\
\hline Urine & $\begin{array}{l}\text { Steroid hormone } \\
\text { metabolism }\end{array}$ & MEKC-ESI-MS partial filling & Steroids & [57] \\
\hline $\begin{array}{l}\text { Plasma, urine and } \\
\text { cerebrospinal fluid }\end{array}$ & $\begin{array}{l}\text { Complex regional pain } \\
\text { syndrome }\end{array}$ & $\begin{array}{l}\text { PB-DS-PB coating: BGE, } 200 \mathrm{mM} \text { sodium phosphate }(\mathrm{pH} \\
6.0 \text { ); injection, } 35 \text { mbar for } 10 \mathrm{~s} \text {; detection, UV at } 200 \mathrm{~nm} \text {, } \\
-10 \mathrm{kV}, 25 \mathrm{C} \text { - PB-PVS coating: BGE, } 1 \mathrm{M} \text { Formic acid ( } \mathrm{pH} \\
\text { 1.8); sample injection, } 90 \text { mbar for } 90 \mathrm{~s} \text {; preinjection, } \\
\text { ammonium hydroxide ( } 12.5 \% \text { ) at } 50 \text { mbar for } 9 \mathrm{~s} ; 30 \mathrm{kV} \text {, } \\
25 \mathrm{C}\end{array}$ & $\begin{array}{l}\text { Organic acids and } \\
\text { amino acids }\end{array}$ & {$[58]$} \\
\hline Saliva & Oxidative stress & Microchip $30 \mathrm{mM}$ borate buffer, pH 9.5, $30 \mathrm{kV}$ & DHBA & [56] \\
\hline Urine & Diabetes & CD-MEKC and CZE & Antioxidants & [11] \\
\hline Urine & $\begin{array}{l}\text { Schistosoma mansoni } \\
\text { infection }\end{array}$ & $\begin{array}{l}\text { EKC } 25 \mathrm{mM} \text { sodium borate, } 75 \mathrm{mM} \text { SDS and } 6.25 \mathrm{mM} \\
\text { sulfated b-CD, pH 9,5, } 18 \mathrm{kV}, 20 \mathrm{C} \text {. CZE coated capillary } \\
0.2 \mathrm{M} \text { phosphoric acid, } 10 \% \mathrm{MeOH}, \mathrm{pH} 6,2,-20 \mathrm{kV}, 25 \mathrm{C}\end{array}$ & Many & {$[3]$} \\
\hline Human bile & Liver transplantation & $\begin{array}{l}10 \mathrm{mM} \text { sodium borate, } 10 \mathrm{mM} \text { sodium dihydrogen, } \\
\text { phosphate adjusted to } \mathrm{pH} 7 \text { with diluted phosphoric acid, } \\
\text { to which } 50 \mathrm{mM} \text { SDS, } 5 \mathrm{mM} \text { b-CD and } 5 \mathrm{mM} \text { HP-b-CD, } 10 \% \\
(\mathrm{v} / \mathrm{v}) \mathrm{CAN}, 20 \% \mathrm{MeOH}, 25 \mathrm{kV}, 30 \mathrm{C}\end{array}$ & Bile acids & [31] \\
\hline Rat urine & $\begin{array}{l}\text { New method to improve } \\
\text { positive charge in acids }\end{array}$ & CE-ESI-MS BGE 1 M FA. SL 50/50 $\mathrm{H}_{2} \mathrm{O} / \mathrm{MeOH} 0.1 \%$ FA, $30 \mathrm{kV}$ & Carboxylic acids & [59] \\
\hline E. coli & $\begin{array}{l}\text { Strategy to find } \\
\text { low-abundance } \\
\text { metabolites }\end{array}$ & $\begin{array}{l}\text { CE-ESI-ITMS BGE } 1 \text { M FA. SL } 1: 1 \mathrm{H}_{2} \mathrm{O} / \mathrm{MeOH}, 0,1 \% \text { FA. } \\
23 \mathrm{kV}, 20 \mathrm{C}\end{array}$ & Amino acids & [60] \\
\hline Urine & Obese rats & CEC with gradient elution & & [40] \\
\hline Human red-cell & Hypoxia & Mathematical model compared with CE-MS & $\begin{array}{l}\text { Metabolites of } \\
\text { glycolysis }\end{array}$ & [61] \\
\hline $\begin{array}{l}\text { Human cerebrospinal } \\
\text { fluid }\end{array}$ & Neurobiological disorders & $\begin{array}{l}\text { CE-ESI-TOFMS - modification of the silica-wall with } \\
\text { 1-(4-iodobutyl)4-aza-1-azoniabicyclo[2,2,2]octane iodide, } \\
\text { also named M7C4I, has successfully been used to } \\
\text { deactivate the fused silica wall and generate a stable } \\
\text { reversed electroosmotic flow }\end{array}$ & Kynurenic acid & {$[62]$} \\
\hline Mouse liver & $\begin{array}{l}\text { Acetaminophen-induced } \\
\text { hepatotoxicity }\end{array}$ & $\begin{array}{l}\text { CE-TOFMS cationic - BGE } 1 \mathrm{M} \text { formic acid. SL } 1: 1 \\
\mathrm{H}_{2} \mathrm{O} / \mathrm{MeOH}, 0.5 \mathrm{M} \text { reserpine, } 30 \mathrm{kV}, 20 \mathrm{C} \text { CE-TOFMS } \\
\text { anionic, cap cationic polymer-coated SMILE }(+) \text { - BGE } \\
50 \mathrm{mM} \text { ammonium acetate, pH 8.5, SL ammonium acetate } \\
(5 \mathrm{mM}), 1: 1 \mathrm{MeOH} / \mathrm{H}_{2} \mathrm{O}, 20 \mathrm{M} \text { PIPES, } 1 \mathrm{M} \text { reserpine, }-30 \mathrm{kV} \text {, } \\
20 \mathrm{C}\end{array}$ & Ophthalmic acid & [63] \\
\hline E. coli & $\begin{array}{l}\text { Discover novel enzymatic } \\
\text { activities }\end{array}$ & - & $\begin{array}{l}\text { Sugars/sugars } \\
\text { phosphates }\end{array}$ & {$[64]$} \\
\hline Urine & Study of urine stability & $\begin{array}{l}\text { Sodium borate/SDS/sulphated b-cyclodextrin } \\
(25 / 75 / 6.25 \mathrm{mM}), \mathrm{pH} 9.50 ; 18 \mathrm{kV}, 20 \mathrm{C}, 5 \mathrm{~s}(0.5 \mathrm{psi}) ; 200 \mathrm{~nm}\end{array}$ & $\begin{array}{l}\text { Urea, creatinine, } \\
\text { phenylalanine, } \\
\text { hippuric acid, uric acid }\end{array}$ & {$[65]$} \\
\hline
\end{tabular}


Table 1 (Continued)

\begin{tabular}{|c|c|c|c|c|}
\hline Fluid & Pathology & Method & Markers & Reference \\
\hline In vitro assay & $\begin{array}{l}\text { Approach designed to } \\
\text { reconstitute a metabolic } \\
\text { pathway }\end{array}$ & $\begin{array}{l}\text { CE-ESI-MS cationic polymer (polybrene)-coated capillary } \\
\text { - BGE } 50 \mathrm{mM} \text { ammonium acetate, pH } 8.5 \text { - SL } 5 \mathrm{mM} \\
\text { ammonium acetate in } 50 \%(\mathrm{v} / \mathrm{v}) \text { methanol-water, }-30 \mathrm{kV} \text {, } \\
20 \mathrm{C}\end{array}$ & Glycolysis metabolites & [67] \\
\hline E. coli & C-13-labeling experiment & CE-TOF-MS & Amino acids & {$[66]$} \\
\hline Bacilus subtilis extracts & $\begin{array}{l}\text { Changes during B. subtilis } \\
\text { sporulation }\end{array}$ & & 1692 metabolites & [41] \\
\hline Bacilus subtilis extracts & $\begin{array}{l}\text { Comprehensive analysis of } \\
\text { metabolic intermediates }\end{array}$ & $\begin{array}{l}\text { CE-ESI-MS cationic polymer (polybrene)-coated capillary } \\
\text { - BGE } 50 \mathrm{mM} \text { ammonium acetate, } \mathrm{pH} 9.0\end{array}$ & 32 carboxylic acids & [68] \\
\hline
\end{tabular}

matching with the standard library alone, the proportion increased to $52.2 \%$ with this method. However, only the description of the procedure, but not the list of metabolites is publicly available.

Kenneth et al. [52] introduced a multivariate strategy for de novo quantification of cationic/zwitterionic metabolites using capillary electrophoresis-electrospray ionization-mass spectrometry (CE-ESI-MS) based on fundamental molecular, thermodynamic, and electrokinetic properties of an ion. The applicability of the multivariate model to quantify micromolar levels of metabolites spiked in red blood cell lysates was also examined by CE-ESI-MS without significant matrix effects caused by involatile salts and/or major co-ion interferences.

To conclude, it is necessary to comment that there are some publications comparing different analytical techniques. Büscher et al. [53] developed a systematic cross-platform comparison of different separation and detection methods for quantitative metabolomics. Using a defined mixture of 91 metabolites (covering glycolysis, pentose phosphate pathway, the tricarboxylic acid (TCA) cycle, redox metabolism, amino acids, and nucleotides), they compared six separation methods designed for the analysis of these mostly very polar primary metabolites, two methods each for gas chromatography (GC), liquid chromatography (LC), and capillary electrophoresis (CE). According to their conclusions, for analyses on a single platform, LC provides the best combination of both versatility and robustness. If a second platform can be used, it is best complemented by GC. In our experience, interesting information can be obtained from this type of synthetic mixtures, however, they do not reproduce the real problems in complex biological matrices and it is there where capillary electrophoresis can find its main application. Urine contains an important amount of polar or ionic compounds poorly retained in reversed phase LC. The aqueous sample should be diluted in a higher proportion of organic solvent to analyse in HILIC mode, however, frequently urine is preserved with sodium borate and HILIC mode does not work properly in the presence of salts. In addition, in GC it produces a huge peak of urea that precludes the observation of most of the compounds in the profile. When uricase is employed changes in a number of metabolites have been described. A similar situation happens with cell culture media which contain mainly amino acids, salts and glucose. For that reason CE can be a good complementary separation technique in metabolomics for polar and ionic compounds in biological samples.

Main applications in CE for biological sample fingerprinting are summarized in Table 1 for an easy overview.

\section{Acknowledgements}

The authors gratefully acknowledge the financial support from Ministery of Science and Technology (MCIT) CTQ2008-03779 and Comunidad de Madrid, S-GEN-0247-2006.

\section{References}

[1] Metabolic Profiling: its Role in Biomarker Discovery and Gene Function Analysis, Kluwer Academic Publishers, London, UK, 2003.
[2] O. Fiehn, J. Kopka, P. Dörmann, T. Altmann, R. Trethewey, L. Willmitzer, Metabolite profiling for plant functional genomics, Nat. Biotechnol. 18 (2000) 1157-1161.

[3] I. García-Pérez, P. Whitfield, A. Bartlett, S. Angulo, C. Legido-Quigley, M. Hanna-Brown, C. Barbas, Metabolic fingerprinting of Schistosoma mansoni infection in mice urine with capillary electrophoresis, Electrophoresis 29 (2008) 3201-3206.

[4] M. Monton, T. Soga, Metabolome analysis by capillary electrophoresis-mass spectrometry, J. Chromatogr. A 1168 (2007) 237-246.

[5] R. Ramautar, A. Demirci, G.J. de Jong, Capillary electrophoresis in metabolomics, Trends Anal. Chem. 25 (2006) 455-466

[6] R. Ramautar, G. Somsen, G. de Jong, CE-MS in metabolomics, Electrophoresis 30 (2009) 276-291.

[7] I. García-Pérez, M. Vallejo, A. García, C. Legido-Quigley, C. Barbas, Metabolic fingerprinting with capillary electrophoresis, J. Chromatogr. A 1204 (2008) 130-139.

[8] M.J. Markuszewski, W. Struck, M. Waszczuk-Jankowska, R. Kaliszan, Metabolomic approach for determination of urinary nucleosides as potential tumor markers using electromigration techniques, Electrophoresis 31 (2010) 2300-2310.

[9] C. Guillo, D. Barlow, D. Perrett, M. Hanna-Brown, Micellar electrokinetic capillary chromatography and data alignment analysis: a new tool in urine profiling J. Chromatogr. A 1027 (2004) 203-212.

[10] A. García, C. Barbas, R. Aguilar, M. Castro, Capillary electrophoresis for rapid profiling of organic acidurias, Clin. Chem. 44 (1998) 1905-1911.

[11] C. Barbas, M. Vallejo, A. García, D. Barlow, M. Hanna-Brown, Capillary electrophoresis as a metabolomic tool in antioxidant therapy studies, J. Pharm. Biomed. Anal. 47 (2008) 388-398.

[12] B. Casado, C. Zanone, L. Annovazzi, P. Iadarola, G. Whalen, J. Baraniuk, Urinary electrophoretic profiles from chronic fatigue syndrome and chronic fatigue syndrome/fibromyalgia patients: a pilot study for achieving their normalization, J. Chromatogr. B: Anal. Technol. Biomed. Life Sci. 814 (2005) 43-51.

[13] A. Kassidas, J.F. MacGregor, P.A. Taylor, Synchronization of batch trajectories using dynamic time warping, AIChE J. 44 (1998) 864-875.

[14] N.-P.V. Nielsena, J.M. Carstensenb, J. Smedsgaard, Aligning of single and multiple wavelength chromatographic profiles for chemometric data analysis using correlation optimised warping, J. Chromatogr. A 805 (1998) 17-35.

[15] G.Tomasi, F. van den Bergand, C. Andersson, Correlation optimized warping and dynamic time warping as preprocessing methods for chromatographic data, J. Chemom. 18 (2004) 231-241.

[16] A. van Nederkassel, M. Daszykowski, P. Eilers, Y. Heyden, A comparison of three algorithms for chromatograms alignment, J. Chromatogr. A 1118 (2006) 199-210.

[17] P. Eilers, Parametric time warping, Anal. Chem. 76 (2004) 404-411.

[18] E. Szymańska, M. Markuszewski, X. Capron, A. van Nederkassel, Y. Vander Heyden, M. Markuszewski, K. Krajka, R. Kaliszan, Evaluation of different warping methods for the analysis of CE profiles of urinary nucleosides, Electrophoresis 28 (2007) 2861-2873.

[19] E. Szymańska, M. Markuszewski, X. Capron, A. van Nederkassel, Y. Heyden, M. Markuszewski, K. Krajka, R. Kaliszan, Increasing conclusiveness of metabonomic studies by chem-informatic preprocessing of capillary electrophoretic data on urinary nucleoside profiles, J. Pharm. Biomed. Anal. 43 (2007) 413-420.

[20] A. Soria, B. Wright, D. Goodall, J. Wilson, Data processing in metabolic fingerprinting by CE-UV: application to urine samples from autistic children, Electrophoresis 28 (2007) 950-964.

[21] R. Bro, C.A. Andersson, H.A.L. Kiers, PARAFAC2: Part II. Modeling chromatographic data with retention time shifts, J. Chemom. 13 (1999) 295-309.

[22] V. Pravdova, B. Walczak, D.L. Massart, A comparison of two algorithms for warping of analytical signals, Anal. Chim. Acta 456 (2002) 77-92.

[23] M. Vallejo, S. Angulo, D. García-Martínez, A. García, C. Barbas, New perspective of diabetes response to an antioxidant treatment through metabolic fingerprinting of urine by capillary electrophoresis, J. Chromatogr. A 1187 (2008) 267-274.

[24] F. Rupérez, D. García-Martínez, B. Baena, N. Maeso, A. Cifuentes, C. Barbas, E. Herrera, Evolution of oxidative stress parameters and response to oral vitamins E and C in streptozotocin-induced diabetic rats, J. Pharm. Pharmacol. 60 (2008) 871-878.

[25] F. Ruperez, D. Garcia-Martinez, B. Baena, N. Maeso, M. Vallejo, S. Angulo, A. Garcia, E. Ibañez, F. Señorans, A. Cifuentes, C. Barbas, Dunaliella salina extract effect on diabetic rats: metabolic fingerprinting and target metabolite analysis, J. Pharm. Biomed. Anal. 49 (2009) 786-792. 
[26] I. Garcia-Perez, M. Earll, S. Angulo, C. Barbas, C. Legido-Quigley, Chemometric analysis of urine fingerprints acquired by liquid chromatography-mass spectrometry and capillary electrophoresis: application to the schistosomiasis mouse model, Electrophoresis 31 (2010) 2349-2355.

[27] I. Garcia-Perez, S. Angulo, J. Utzinger, E. Holmes, C. Legido-Quigley, C. Barbas, Chemometric and biological validation of a capillary electrophoresis metabolomic experiment of Schistosoma mansoni infection in mice, Electrophoresis 31 (2010) 2338-2348.

[28] S. Angulo, I. García-Pérez, C. Legido-Quigley, C. Barbas, The autocorrelation matrix probing biochemical relationships after metabolic fingerprinting with CE, Electrophoresis 30 (2009) 1221-1227.

[29] I. Garcia-Perez, A. Couto Alves, S. Angulo, J. Li, J. Utzinger, T. Ebbels, C. LegidoQuigley, J. Nicholson, E. Holmes, C. Barbas, Bidirectional correlation of NMR and capillary electrophoresis fingerprints: a new approach to investigating Schistosoma mansoni infection in a mouse model, Anal. Chem. 82 (2010) 203-210.

[30] C. Balderas, A. Villaseñor, A. García, F. Rupérez, E. Ibañez, J. Señorans, J. GuerreroFernández, I. González-Casado, R. Gracia-Bouthelier, C. Barbas, Metabolomic approach to the nutraceutical effect of rosemary extract plus omega-3 PUFAs in diabetic children with capillary electrophoresis, J. Pharm. Biomed. Anal. 53 (2010) 1298-1304.

[31] K. Papaspyridonos, I. Garcia-Perez, S. Angulo, P. Domann, H. Vilca-Melendez, N. Heaton, G. Murphy, E. Holmes, C. Barbas, C. Legido-Quigley, Fingerprinting of human bile during liver transplantation by capillary electrophoresis, J. Sep. Sci. 31 (2008) 3058-3064.

[32] A. Zamfir, Recent advances in sheathless interfacing of capillary electrophoresis and electrospray ionization mass spectrometry, J. Chromatogr. A 1159 (2007) $2-13$.

[33] T. Lapainis, S. Rubakhin, J. Sweedler, Capillary electrophoresis with electrospray ionization mass spectrometric detection for single-cell metabolomics, Anal. Chem. 81 (2009) 5858-5864.

[34] A. Staub, J. Schappler, S. Rudaz, J. Veuthey, CE-TOF/MS: fundamental concepts, instrumental considerations and applications, Electrophoresis 30 (2009) $1610-1623$.

[35] T. Soga, D. Heiger, Amino acid analysis by capillary electrophoresis electrospray ionization mass spectrometry, Anal. Chem. 72 (2000) 1236-1241.

[36] R. Ramautar, A. van der Plas, E. Nevedomskaya, R. Derks, G. Somsen, G. de Jong, J. van Hilten, A. Deelder, O. Mayboroda, Explorative analysis of urine by capillary electrophoresis-mass spectrometry in chronic patients with complex regional pain syndrome, J. Proteome Res. 8 (2009) 5559-5567.

[37] Y. Minami, T. Kasukawa, Y. Kakazu, M. Iigo, M. Sugimoto, S. Ikeda, A. Yasui, G. van der Horst, T. Soga, H. Ueda, Measurement of internal body time by blood metabolomics, Proc. Natl. Acad. Sci. U.S.A 106 (2009) 9890-9895.

[38] T. Soga, Y. Ueno, H. Naraoka, K. Matsuda, M. Tomita, T. Nishioka, Pressureassisted capillary electrophoresis electrospray ionization mass spectrometry for analysis of multivalent anions, Anal. Chem. 74 (2002) 6224-6229.

[39] K. Harada, E. Fukusaki, A. Kobayashi, Pressure-assisted capillary electrophoresis mass spectrometry using combination of polarity reversion and electroosmotic flow for metabolomics anion analysis, J. Biosci. Bioeng. 101 (2006) 403-409.

[40] G. Xie, M. Su, P. Li, X. Gu, C. Yan, Y. Qiu, H. Li, W. Jia, Analysis of urinary metabolites for metabolomic study by pressurized CEC, Electrophoresis 28 (2007) 4459-4468.

[41] T. Soga, Y. Ohashi, Y. Ueno, H. Naraoka, M. Tomita, T. Nishioka, Quantitative metabolome analysis using capillary electrophoresis mass spectrometry, J. Proteome Res. 2 (2003) 488-494.

[42] F. Benavente, R. van der Heijden, U. Tjaden, J. van der Greef, T. Hankemeier, Metabolite profiling of human urine by CE-ESI-MS using separation electrolytes at low pH, Electrophoresis 27 (2006) 4570-4584.

[43] R. Ramautar, J. Toraño, G. Somsen, G. de Jong, Evaluation of CE methods for global metabolic profiling of urine, Electrophoresis 31 (2010) 2319-2327.

[44] T. Soga, K. Igarashi, C. Ito, K. Mizobuchi, H. Zimmermann, M. Tomita, Metabolomic profiling of anionic metabolites by capillary electrophoresis mass spectrometry, Anal. Chem. 81 (2009) 6165-6174.

[45] E. Allard, D. Bäckström, R. Danielsson, P. Sjöberg, J. Bergquist, Comparing capillary electrophoresis-mass spectrometry fingerprints of urine samples obtained after intake of coffee, tea, or water, Anal. Chem. 80 (2008) 8946-8955.

[46] R. Lee, D. West, S. Phillips, P. Britz-McKibbin, Differential metabolomics for quantitative assessment of oxidative stress with strenuous exercise and nutritional intervention: thiol-specific regulation of cellular metabolism with N-acetyl-L-cysteine pretreatment, Anal. Chem. 82 (2010) 2959-2968.

[47] M. Sugimoto, D. Wong, A. Hirayama, T. Soga, M. Tomita, Capillary electrophoresis mass spectrometry-based saliva metabolomics identified oral, breast and pancreatic cancer-specific profiles, Metabolomics 6 (2010) 78-95.

[48] R. Lee, P. Britz-McKibbin, Metabolomic studies of radiation-induced apoptosis of human leukocytes by capillary electrophoresis-mass spectrometry and flow cytometry: adaptive cellular responses to ionizing radiation, Electrophoresis 31 (2010) 2328-2337.
[49] A. Hirayama, K. Kami, M. Sugimoto, M. Sugawara, N. Toki, H. Onozuka, T Kinoshita, N. Saito, A. Ochiai, M. Tomita, H. Esumi, T. Soga, Quantitative metabolome profiling of colon and stomach cancer microenvironment by capillary electrophoresis time-of-flight mass spectrometry, Cancer Res 69 (2009) 4918-4925.

[50] M. Sugimoto, A. Hirayama, T. Ishikawa, M. Robert, R. Baran, K. Uehara, K. Kawai, T. Soga, M. Tomita, Differential metabolomics software for capillary electrophoresis-mass spectrometry data analysis, Metabolomics 6 (2009) 27-41.

[51] M. Sugimoto, A. Hirayama, M. Robert, S. Abe, T. Soga, M. Tomita, Prediction of metabolite identity from accurate mass, migration time prediction and isotopic pattern information in CE-TOFMS data, Electrophoresis 31 (2010) 2311-2318.

[52] K. Chalcraft, R. Lee, C. Mills, P. Britz-McKibbin, Virtual quantification of metabolites by capillary electrophoresis-electrospray ionization-mass spectrometry: predicting ionization efficiency without chemical standards, Anal. Chem. 81 (2009) 2506-2515.

[53] J. Büscher, D. Czernik, J. Ewald, U. Sauer, N. Zamboni, Cross-platform comparison of methods for quantitative metabolomics of primary metabolism, Anal. Chem. 81 (2009) 2135-2143.

[54] R. Lee, P. Britz-McKibbin, Differential rates of glutathione oxidation for assessment of cellular redox status and antioxidant capacity by capillary electrophoresis-mass spectrometry: an elusive biomarker of oxidative stress, Anal. Chem. 81 (2009) 7047-7056.

[55] R. Ramautar, O.A. Mayboroda, R.J. Derks, C. van Nieuwkoop, J.T. van Dissel, G.W. Somsen, A.M. Deelder, G.J. de Jong, Capillary electrophoresis-time of flight-mass spectrometry using noncovalently bilayer-coated capillaries for the analysis of amino acids in human urine, Electrophoresis 29 (2008) 2714-2722.

[56] D.J. Marchiarullo, J.Y. Lim, Z. Vaksman, J.P. Ferrance, L. Putcha, J.P. Landers, Towards an integrated microfluidic device for spaceflight clinical diagnostics microchip-based solid-phase extraction of hydroxyl radical markers, J. Chromatogr. A 1200 (2008) 198-203.

[57] H. Sirén, T. Seppänen-Laakso, M. Oresic, Capillary electrophoresis with UV detection and mass spectrometry in method development for profiling metabolites of steroid hormone metabolism, J. Chromatogr. B: Anal. Technol. Biomed. Life Sci. 871 (2008) 375-382.

[58] R. Ramautar, O. Mayboroda, A. Deelder, G. Somsen, G. de Jong, Metabolic analysis of body fluids by capillary electrophoresis using noncovalently coated capillaries, J. Chromatogr. B: Anal. Technol. Biomed. Life Sci. 871 (2008) 370-374.

[59] W.C. Yang, F.E. Regnier, J. Adamec, Comparative metabolite profiling of carboxylic acids in rat urine by CE-ESI MS/MS through positively pre-charged and (2)H-coded derivatization, Electrophoresis 29 (2008) 4549-4560.

[60] R. Lee, A.S. Ptolemy, L. Niewczas, P. Britz-McKibbin, Integrative metabolomics for characterizing unknown low-abundance metabolites by capillary electrophoresis-mass spectrometry with computer simulations, Anal. Chem. 79 (2007) 403-415.

[61] A. Kinoshita, K. Tsukada, T. Soga, T. Hishiki, Y. Ueno, Y. Nakayama, M. Tomita, M. Suematsu, Roles of hemoglobin allostery in hypoxia-induced metabolic alterations in erythrocytes: simulation and its verification by metabolome analysis, J. Biol. Chem. 282 (2007) 10731-10741.

[62] B. Arvidsson, N. Johannesson, A. Citterio, P.G. Righetti, J. Bergquist, High throughput analysis of tryptophan metabolites in a complex matrix using capillary electrophoresis coupled to time-of-flight mass spectrometry, J. Chromatogr. A 1159 (2007) 154-158.

[63] T. Soga, R. Baran, M. Suematsu, Y. Ueno, S. Ikeda, T. Sakurakawa, Y. Kakazu, T. Ishikawa, M. Robert, T. Nishioka, M. Tomita, Differential metabolomics reveals ophthalmic acid as an oxidative stress biomarker indicating hepatic glutathione consumption, J. Biol. Chem. 281 (2006) 16768-16776.

[64] N. Saito, M. Robert, S. Kitamura, R. Baran, T. Soga, H. Mori, T. Nishioka, M. Tomita, Metabolomics approach for enzyme discovery, J. Proteome Res. 5 (2006) 1979-1987.

[65] C. Guillo, D. Perrett, M. Hanna-Brown, Validation and further optimisation of a cyclodextrin-modified micellar electrokinetic capillary chromatography method for urine profiling, Chromatogr. Suppl. 59 (2004) S157-S164.

[66] Y. Toya, N. Ishii, T. Hirasawa, M. Naba, K. Hirai, K. Sugawara, S. Igarashi, K. Shimizu, M. Tomita, T. Soga, Direct measurement of isotopomer of intracellular metabolites using capillary electrophoresis time-of-flight mass spectrometry for efficient metabolic flux analysis, J. Chromatogr. A 1159 (2007) 134-141.

[67] A. Itoh, Y. Ohashi, T. Soga, H. Mori, T. Nishioka, M. Tomita, Application of capillary electrophoresis-mass spectrometry to synthetic in vitro glycolysis studies, Electrophoresis 25 (2004) 1996-2002.

[68] T. Soga, Y. Ueno, H. Naraoka, Y. Ohashi, M. Tomita, T. Nishioka, Simultaneous determination of anionic intermediates for Bacillus subtilis metabolic pathways by capillary electrophoresis electrospray ionization mass spectrometry, Anal. Chem. 74 (2002) 2233-2239. 